\title{
Use of Mannitol Inhalation Challenge in Assessment of Cough
}

\author{
Sheldon Spector
}

Received: 13 August 2009/Accepted: 24 August 2009/Published online: 16 September 2009

(C) The Author(s) 2009. This article is published with open access at Springerlink.com

\begin{abstract}
Bronchial provocation testing uses a variety of direct and indirect inhalational challenges to evaluate airway hyperreactivity. Mannitol, a simple, easy-to-administer hypertonic stimulus available in many countries, is currently under review by the FDA in the US. Healthy subjects show no airway response to inhaled mannitol; asthmatic patients respond with airway narrowing similar to challenges with hypertonic saline and exercise. Mannitol challenge also has a tussive effect that is independent of bronchoconstriction, suggesting different physiologic pathways. Patients with chronic cough show increased sensitivity to mannitol, and mannitol testing may be useful for evaluating heterogeneity in the cough response.
\end{abstract}

Keywords Mannitol - Bronchoprovocation ·

Inhalation challenge test $\cdot$ Cough $\cdot$ Asthma

\section{Introduction}

Bronchial provocation testing may be employed for a variety of purposes, but it is most commonly used to assess the tendency of the bronchi to narrow in response to exogenous stimuli. Testing can be done by direct and indirect challenges using a number of different agents [1] (Table 1).

\section{S. Spector}

David Geffen School of Medicine at UCLA, Los Angeles, CA, USA

\section{S. Spector $(\bowtie)$}

California Allergy and Asthma Medical Group, 11645 Wilshire, Suite 1155, Los Angeles, CA 90025, USA

e-mail: spector@calallergy.com
Methacholine aerosol inhalation is the prototype of a direct inhalation challenge. Bronchoconstriction following inhalation results from the direct action of methacholine on acetylcholine receptors in airway smooth muscle. Methacholine bronchoprovocation challenge is highly sensitive in identifying bronchial hyperreactivity, and a negative test is often used to exclude asthma [1].

Indirect challenges simulate airway responses to specific physiologic situations such as exercise [1,2]. The most recent indirect challenge is the mannitol (MAN) dry powder challenge, which is available as a standardized test kit in some countries [3]. It is currently in review, but not approved, by the Food and Drug Administration for use in the US. The kit includes prefilled capsules with mannitol in escalating doses, to be administered in an easy-to-use, handheld dry powder device. The safety and efficacy of MAN dry powder inhalation challenge have been established in large Phase III trials involving healthy subjects and patients with asthma $[3,4]$.

\section{Mannitol Inhalation Challenge}

Mannitol is a hypertonic stimulus, and inhalation is thought to exert an osmotic effect within the airway that subsequently leads to the release of inflammatory mediators from mast cells, basophils, and human lung fragments [5]. In asthmatic patients this leads to airway narrowing similar to that observed with hypertonic saline and exercise challenge. Healthy, nonasthmatic subjects show no airway response to inhaled mannitol [3-5].

A positive response to mannitol is used to identify patients who have exercise-induced bronchoconstriction (EIB), with or without chronic symptoms of asthma. A negative response suggests that asthma is not present or, in 
Table 1 Agents commonly used in bronchial provocation testing [1]

\begin{tabular}{ll}
\hline Indirect challenges & Direct challenges \\
\hline Adenosine monophosphate (AMP) & Acetylcholine \\
Eucapnic voluntary hyperventilation $(\mathrm{EVH})$ & Carbachol \\
Exercise & Histamine \\
Hypertonic saline & Methacholine \\
Mannitol $^{\mathrm{a}}$ &
\end{tabular}

${ }^{\text {a }}$ Not yet approved in the US

some cases, that it is mild with intermittent symptoms or well-treated [3, 4, 6].

The simplicity of the mannitol challenge suggests that there may be some advantages over other bronchoprovocation tests. Mannitol is given by a handheld dry powder inhaler (DPI), so there is no specialized equipment required for the doctor's office. Use of the DPI also makes the test easy for patients to learn and permits the test to be conducted quickly [4, 6]. These advantages were recently confirmed in a study assessing the sensitivity and specificity of mannitol to identify EIB as a manifestation of bronchial hyperreactivity in a highly selected population of possible asthmatics with a normal $\mathrm{FEV}_{1}$ [4]. A comparison was made with methacholine. Mannitol and methacholine were therapeutically equivalent to identify EIB and establish a clinician's diagnosis of asthma. However, in addition to not requiring specialized equipment, the mannitol challenge was more reproducible and took less time to perform than the methacholine test [4]. Only $43.5 \%$ of the subjects had a positive response to exercise as defined by at least a $10 \%$ reduction in $\mathrm{FEV}_{1}$ on at least one of two challenges [4].

To better understand the mechanism associated with a mannitol challenge, Brannan et al. [5] studied 12 asthmatic and 9 nonasthmatic subjects for evidence of mast cell activation and leukotriene release. They measured urinary excretion of leukotriene (LT) $\mathrm{E}_{4}$ and prostaglandin (PG) $\mathrm{D}_{2}$ metabolites (and mast cell markers) N-methylhistamine and $9 \alpha, 11 \beta, \mathrm{PGF}_{2}$ at $60 \mathrm{~min}$ before and $90 \mathrm{~min}$ after mannitol inhalation. Airway narrowing provoked by mannitol challenge in asthmatic subjects was associated with increased urinary excretion of $9 \alpha, 11 \beta, \mathrm{PGF}_{2}$. Excretion of this $\mathrm{PGD}_{2}$ metabolite is an index of mast cell activation, and following mannitol challenge it is probably secondary to increased osmolarity of the airway surface liquid [5]. Urinary excretion of N-methylhistamine was not significantly affected by mannitol.

The data support earlier work showing changes in airway sensitivity to mannitol in the presence of various mediator antagonists. Interestingly, in subjects with asthma the histamine antagonist fexofenadine $(2 \times 180 \mathrm{mg}$ over $14 \mathrm{~h})$ reduced airway sensitivity to mannitol, while the leukotriene antagonist montelukast $(3 \times 10 \mathrm{mg}$ over $36 \mathrm{~h})$ caused a faster recovery of lung function to baseline postchallenge but had no effect on sensitivity [7]. The same mediators and time sequence of release have been reported with exercise-induced asthma, suggesting a similar mechanism of action [5].

The mast cell stabilizer nedocromil sodium $(8 \mathrm{mg}$, 10 min prechallenge), also has been reported to significantly reduce bronchoconstriction to mannitol inhalation in subjects with exercise-induced asthma [8]. More recently, both cromolyn sodium (40 mg, $15 \mathrm{~min}$ prechallenge), another mast cell stabilizer, and formoterol (24 mcg, 15 min prechallenge), a long-acting bronchodilator, were shown to protect against the change in $9 \alpha, 11 \beta, \mathrm{PGF}_{2}$ concomitant with a reduction in the mannitol-induced fall in $\mathrm{FEV}_{1}$ (by 35 and 95\%, respectively) [9].

\section{Using Mannitol to Assess Cough}

One of the early observations in the development of the mannitol challenge was that it has a tussive effect. Like other indirect bronchoprovocation challenges, asthmatics cough more than healthy controls in response to mannitol, and the tussive effect is independent of the bronchoconstrictive effect, suggesting different physiological mechanisms [10]. However, the simplicity of the mannitol challenge compared to other indirect bronchoprovocation tests makes it a potentially useful tool for evaluating airways hyperresponsiveness and cough sensitivity.

A pilot study looked at the dose of mannitol needed to provoke two or five coughs in 13 subjects with nonasthmatic chronic cough compared to 16 healthy subjects [11]. The subjects with chronic cough showed a heightened cough response to challenge (i.e., less mannitol needed to provoke cough); none had airway responsiveness to mannitol. The findings support the hypotheses that (1) mannitol-provoked cough is increased in patients with nonasthmatic chronic cough, and (2) mannitol-provoked cough is independent of mannitol-provoked bronchoconstriction. The cough response may involve indirect activation of mast cells in the superficial airway and subsequent release or mediators that, in turn, activate local cough receptors [11]. The separate observation that nedocromil sodium failed to attenuate mannitol-induced cough, in contrast to mannitol-induced bronchoconstriction, supports the lack of direct involvement of mast cell pathways [12].

Similar findings have been reported for capsaicin, a common test for studying induced cough. Capsaicin, the "hot" ingredient in red pepper, is known to stimulate unmyelinated C fibers in the sensory nervous system [13]. Studies have shown that coughing can be induced by capsaicin inhalation in a dose-dependent manner in healthy 
subjects and those with mild asthma, and that capsaicin challenge does not cause dyspnea and has no effect on the $\mathrm{FEV}_{1}$. It has been demonstrated that capsaicin-induced cough can be blocked by local anesthetic [14-16] but not by pretreatment with the mast cell stabilizer cromolyn sodium [17]. These data support the separation of neuronal pathways of coughing from bronchoconstrictive airway responses directly related to inflammatory mediators.

Patients with increased coughing as a symptom represent a heterogeneous population. Mannitol inhalation challenge may be useful for diagnosing and/or managing at least three types of patients described in the literature.

\section{Asthma Patients}

Koskela et al. [10] analyzed the cough response to three airway challenges in order to clarify whether the recording of the provoked cough would be beneficial in the management of asthma. They used isotonic histamine, hypertonic saline solution, and hypertonic histamine, all delivered by an ultrasonic nebulizer using the 2-min tidal breathing method. Coughing during isotonic histamine challenge seemed to be a manifestation of bronchoconstriction, but recording the cough did not provide additional information to airflow measurements [10]. Frequent coughing occurred during the hypertonic challenges in the absence of bronchoconstriction. Sensitivity to the cough-provoking effect of hypertonic challenges was enhanced in patients with asthma and was unrelated to airway hyperresponsiveness. These investigators, therefore, advocated that cough assessment during hypertonic challenges could help to identify those patients with cough-variant asthma [10].

\section{Patients with Odor Intolerance}

These patients show increased coughing and increased cough sensitivity to inhaled capsaicin. Johansson et al. [18] investigated the relationship between cough sensitivity to inhaled capsaicin and odor sensitivity using a chemical sensitivity scale for sensory hyperreactivity (CSS-SHR), dividing subjects into four groups with different odor sensitivity according to their CSS-SHR score. Of these, 137 individuals randomly received a capsaicin inhalation test in which the number of coughs encountered 10 min from the start of each inhalation was registered. More than $80 \%$ of subjects with positive capsaicin inhalation scores also had positive CSS-SHR scores; only $5 \%$ of subjects with negative CSS-SHR scores had a positive capsaicin inhalation test. The direct relationship between sensitivity to inhaled capsaicin and a high CSS-SHR score makes it possible to relate subjective data to objective findings [18]. Mannitol challenge of patients with odor insensitivity and dyspnea may support the diagnosis and lead to early and appropriate treatment.
Patients with Suspected EIB

Mannitol-induced coughing was evident in $93 \%$ of 419 subjects studied for suspected EIB as diagnosed by mannitol and methacholine challenges [4]. Of these, $204(49 \%)$ had occasional cough that did not interfere with the challenge, 178 (42\%) had frequent cough that delayed administration of the next dose, and $9(2 \%)$ had severe cough that interfered with the challenge [4].

The studies cited above have shown heterogeneity in the cough response to mannitol. Using a cough counter supplied by Karmel Sonics-Israel, my coworkers and I have evaluated the differences in cough response to mannitol inhalation. Figure 1 illustrates the cough-response variability among three patients. Two individuals had no cough at any time during the challenges, while the other had a cough throughout; all three had positive bronchoprovocation testing with drops in $\mathrm{FEV}_{1}$ by more than $20 \%$ at premaximal doses. The variation in the cough responses probably reflects differences in the underlying mechanisms of airway hyperresponsiveness in these individuals, but more patients should be studied before drawing any conclusions. Similar findings have been reported by Dicpinigaitis et al. [19] who reviewed the safety of capsaicin cough challenges over 20 years of clinical experience. Like the initial results to date with mannitol, no serious adverse events were associated with capsaicin cough-challenge testing, only minor and transient descriptions of throat irritation. However, heterogeneity in the cough response was observed: asthmatics without cough did not differ from healthy volunteers in terms of cough reflux sensitivity to capsaicin, though differences were evident in airway reactivity. The results from mannitol and capsaicin thus support the suggestion that cough and bronchial responsiveness are distinct phenomena mediated through unique neural pathways. Cough monitoring during bronchial challenges may help sort out subtypes of asthma and airway reactivity.

\section{Mannitol as a Treatment for Cystic Fibrosis (CF)}

As a hypertonic agent, mannitol inhalation may have a beneficial effect on mucus elimination in patients with $\mathrm{CF}$. An initial study demonstrated an improvement in lung function related to small airway obstruction and a significant improvement in respiratory symptoms and quality of life after a 2 -week treatment with mannitol in 38 patients [20]. The dose used was $400 \mathrm{mg}$ twice daily.

The suggested mechanism for the positive action of mannitol in CF is the same as that for nebulized hypertonic saline treatment, i.e., osmotically induced water influx into the bronchial lumen thereby increasing the hydration of airway mucus so that it is cleared more effectively and 
Fig. 1 Cough monitoring during mannitol bronchial provocation test (BPT). Cough monitoring from four studies on three asthma patients undergoing BPT demonstrates the cough-response variability among patients. The patients were monitored with the PulmoTrack ${ }^{\circledR}$ (Model 3010-CC, KarmelSonix Ltd, Haifa, Israel) throughout the test. a, b Patient whose exposure to mannitol triggered extensive coughing that diminished after albuterol (arrow). This was repeated 2 weeks later with similar phenotype response. c, $\mathbf{d}$ Two patients who did not cough in response to mannitol. All patients had positive BPT with reductions in $\mathrm{FEV}_{1}>20 \%$ at premaximal dose

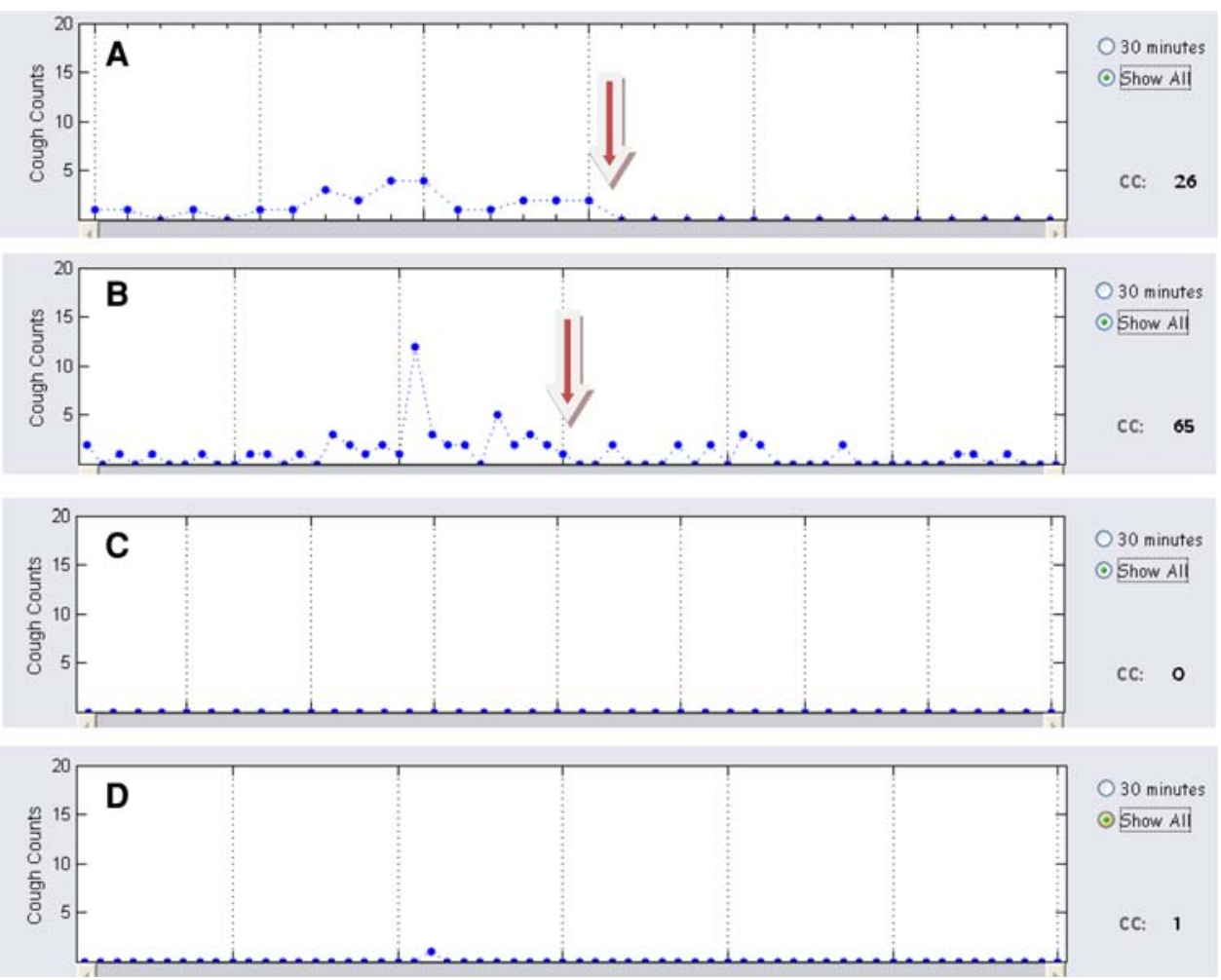

expectorated [20]. Enhanced ciliary clearance of mucus also should result in a sustained reduction in mucus load, thus providing less opportunity for proliferation of bacteria and infection leading to less antibiotic use and fewer hospitalizations. Long-term studies have been proposed and are presently being assessed by investigative protocols.

In summary, mannitol is a simple, easy-to-administer indirect, inhalation challenge test. Sensitivity to mannitol is increased in patients with asthma and in patients with chronic cough, but mannitol-provoked cough occurs via different pathways than mannitol-provoked bronchoconstriction. Mannitol challenge testing may help sort out the heterogeneity in cough and bronchoconstrictive responses in certain patient populations.

Acknowledgment The technical and editorial support of Dr. Judith Farrar is gratefully acknowledged.

Open Access This article is distributed under the terms of the Creative Commons Attribution Noncommercial License which permits any noncommercial use, distribution, and reproduction in any medium, provided the original author(s) and source are credited.

\section{References}

1. Spector SL (ed) (1995) Provocation testing in clinical practice. Marcel Dekker, New York

2. Anderson SD, Brannan JD (2003) Methods for "indirect" challenge tests including exercise, eucapnic voluntary hyperpnea, and hypertonic aerosols. Clin Rev Allergy Immunol 24:27-54
3. Anderson SD, Brannan J, Spring J, Spalding N, Rodwell LT, Chan K, Gonda I, Walsh A, Clark AR (1997) A new method for bronchial-provocation testing in asthmatic subjects using a dry powder of mannitol. Am J Respir Crit Care Med 150:758-765

4. Anderson SD, Charlton B, Weiler JM, Nichols S, Spector SL, Pearlman DS, A305 Study Group (2009) Comparison of mannitol and methacholine to predict exercise-induced bronchoconstriction and a clinical diagnosis of asthma. Respir Res 10:4. doi: 10.1186/1465-9921-10-4

5. Brannan JD, Gulliksson M, Anderson SD, Chew N, Kumlin M (2003) Evidence of mast cell activation and leukotriene release after mannitol inhalation. Eur Respir J 22:1-6

6. Storms W (2009) Challenges in the management of exerciseinduced asthma. Exp Rev Clin Immunol 5:261-269

7. Brannan JD, Anderson SD, Gomes K, King GG, Chan H-K, Seale JP (2001) Fexofenadine decreases sensitivity to and montelukast improves recovery from inhaled mannitol. Am J Respir Crit Care Med 163:1420-1425

8. Brannan JD, Anderson SD, Freed R, Leuppi JD, Koskela H, Chan H-K (2000) Nedocromil sodium inhibits responsiveness to inhaled mannitol in asthmatic subjects. Am J Respir Crit Care Med 161: 2096-2099

9. Brannan JD, Guilliksson M, Anderson SD, Chew N, Seale JP, Kumlin $M$ (2006) Inhibition of mast cell $\mathrm{PGD}_{2}$ release protects against mannitol-induced airway narrowing. Eur Respir J 27:944-950

10. Koskela HO, Kontra KM, Purokivi MK, Randell JT (2005) Interpretation of cough provoked by airway challenges. Chest 128:3329-3335

11. Singapuri A, McKenna S, Brightling CE (2008) The utility of the mannitol challenge in the assessment of chronic cough: a pilot study. Cough 4:10. doi:10.1186/1745-9974-4-10

12. Koskela HO, Martens R, Brannan JD, Anderson SD, Leuppi J, Chan HK (2005) Dissociation in the effect of nedocromil on mannitol-induced cough or bronchoconstriction in asthmatic subjects. Respirology 10:442-448 
13. Caterina MJ, Julius D (2001) The vanilloid receptor: a molecular gateway to the pain pathway. Annu Rev Neurosci 24:487-517

14. Millqvist E (2000) Cough provocation with capsaicin is an objective way to test sensory hyperreactivity in patients with asthma-like symptoms. Allergy 55:546-550

15. Midgren B, Hansson L, Karlsson JA, Simonsson BG, Persson CG (1992) Capsaicin-induced cough in humans. Am Rev Respir Dis 146:347-351

16. Hansson L, Midgren B, Karlsson JA (1994) Effects of inhaled lignocaine and adrenaline on capsaicin-induced cough in humans. Thorax 49:1166-1168
17. Collier JG, Fuller RW (1984) Capsaicin inhalation in man and the effects of sodium cromoglycate. Br J Pharmacol 81:113-117

18. Johansson A, Millqvist E, Nordin S, Bende M (2006) Relationship between self-reported odor intolerance and sensitivity to inhaled capsaicin. Proposed definition of airway sensory hyperreactivity and estimation of its prevalence. Chest 129:1623-1628

19. Dicpinigaitis PV, Alva RV (2005) Safety of capsaicin cough challenge testing. Chest 128:196-202

20. Wills PJ (2007) Inhaled mannitol in cystic fibrosis. Exp Opin Invest Drugs 16:1121-1126

\section{Financial Disclosure/Conflict of Interest Statement}

The authors of this article have no commercial associations (e.g., consultancies, stock ownership, equity interests, patent-licensing arrangements, etc.) that might pose a conflict of interest in connection with the submitted article, except as disclosed on a separate attachment. All funding sources supporting the work and all institutional or corporate affiliations of the authors are acknowledged in a footnote. 